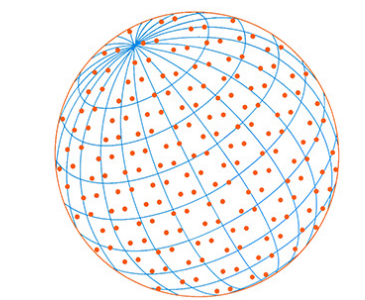

Aerosol and Air Quality Research

\title{
Analysis of Air Quality Changes and Influencing Factors in Changchun during the COVID-19 Pandemic in 2020
}

\author{
Hanbo Gao, Ju Wang*, Tongnan Li, Chunsheng Fang \\ College of New Energy and Environment, Jilin University, Changchun 130012, China
}

\section{ABSTRACT}

To study the air quality changes during the Corona Virus Disease 2019 (COVID-19) lockdown in Changchun, we analyzed the changes in pollution of six major pollutants $\left(\mathrm{PM}_{2.5}, \mathrm{PM}_{10}, \mathrm{SO}_{2}, \mathrm{NO}_{2}\right.$, $\mathrm{O}_{3}, \mathrm{CO}$ ) and correlated them with meteorological parameters, using meteorological data and pollutants concentration data. Regional transport pathways and potential source areas of pollutants were analyzed using the Hybrid Single Particle Lagrangian Integrated Trajectory (HYSPLIT) model and Potential Source Contribution Function (PSCF). The results showed that the concentrations of $\mathrm{PM}_{2.5}, \mathrm{PM}_{10}, \mathrm{SO}_{2}, \mathrm{NO}_{2}, \mathrm{CO}$ were $30.5 \%-53.8 \%$ lower in the Level I period and $49.4 \%-65.0 \%$ lower in the Level II period than in the pre-lockdown period, respectively. Conversely, $\mathrm{O}_{3}$ increased $59.6 \%$ and $58.1 \%$ during Level I and Level II, respectively, compared to the pre-lockdown period. During the 55-day lockdown, daily average concentrations of each pollutant were lower than in previous years on 36-55 days, while $\mathrm{O}_{3}$ was higher on 35 days. The pollutants that decreased in concentration during the lockdown also showed an increase during the Level III period (up to $188.5 \%)$. The maximum daily growth rate of $\mathrm{PM}_{2.5}$ during the lockdown period in 2020 was $16.0 \%$, which was higher than this value in the same period of previous years $(21.8 \%, 21.4 \%, 17.4 \%)$. This shows that the change trend of pollutants during the lockdown period is smoother than in previous years. Temperature and $\mathrm{O}_{3}$ were positively correlated before the lockdown and during Level I and weakly negatively correlated during Level II and Level III. Despite the prevalence of northwest winds in winter, a high percentage of trajectories from other directions (up to $36.8 \%$ ) was observed during the lockdown. Simultaneously, the lockdown reduced the potential source area for $\mathrm{PM}_{2.5}$ (WPSCF $\geq 0.000007$ ), but rebounded after the lockdown was lifted. In conclusion, the lockdown only temporarily reduced the air pollution in Changchun.

Received: March 15, 2021

Revised: May 25, 2021

Accepted: May 30, 2021

${ }^{*}$ Corresponding Author:

wangju@jlu.edu.cn

Keywords: COVID-19, Backward trajectory, WPSCF, Lockdown, Air pollution

\section{INTRODUCTION}

\section{Publisher:}

Taiwan Association for Aerosol Research

ISSN: $1680-8584$ print ISSN: 2071-1409 online

(c) Copyright: The Author(s).

This is an open access article distributed under the terms of the Creative Commons Attribution License (CC BY 4.0), which permits unrestricted use, distribution, and reproduction in any medium, provided the original author and source are cited.

The Corona Virus Disease 2019 (COVID-19) pandemic, which began in late 2019, has gradually spread worldwide and has now engulfed the entire planet. To date (15 May 2021), it has caused more than 162 million global infections and more than 3.35 million deaths. Besides, the pandemic has had a vast social and economic impact on the world (Mofijur et al., 2021). In the wake of the pandemic, China has put in place strict and effective emergency measures to deal with the pandemic, the core of which is the "lockdown", and as a result, the number of new confirmed cases has fallen dramatically, and many people have been prevented from becoming infected (Shen et al., 2020; Tian et al., 2020). Traffic journeys, industrial production, building construction, and even hotels in operation are considerably reduced. We know that human activities such as industry, traffic and living are the primary sources of air pollution emissions, especially in winter (Li et al., 2017; Wen et al., 2020). As a result, the air quality during COVID-19 in China was better than in previous years. Satellite images released by the National Aeronautics and Space Administration (NASA) of the United States of America also point to a significant reduction in China's $\mathrm{NO}_{2}$ 
concentrations due to the reduced frequency of human activities caused by the lockdown.

Air Quality Index (AQI) in three western Chinese cities in February 2020 compared to the same period in 2017-2019. Other analyses of pollution conditions during the pandemic similarly found a significant downward trend in ground-level concentrations of the primary pollutants, both in China and other countries, in different regions (Li et al., 2020; Otmani et al., 2020; Xu et al., 2020).

In order to visualize the details of air quality changes in Changchun during the pandemic, the pandemic was a public health event (including infectious disease pandemics, unexplained mass diseases, food safety and occupational hazards, animal pandemics, and other events seriously affecting public health and life safety) according to the National Emergency Response Plan for Public Emergencies issued by the State Council of China. This is determined by the degree of harm, urgency and development that a public event may cause. It is usually divided into four classes: Level I (particularly severe), Level II (severe), Level III (heavier) and Level IV (general). According to the announcement released by the Jilin Provincial People's Government on its official website, it was known that Jilin launched a Level I response on $25^{\text {th }}$ January 2020, which was downgraded to a Level II response on $26^{\text {th }}$ February and to a Level III response on $20^{\text {th }}$ March, so we divided the study period into four phases: before the city lockdown (1 January-24 January 2020); Level I response (25 January-25 February 2020); Level II response (26 February-19 March 2020); and part of the Level III response period (20 March-20 April 2020), during which the lockdown was largely lifted. The Level I response period includes the Chinese Lunar New Year. On 25 January 2020, Jilin Province entered into the Level I response, with cities taking strict precautionary measures, including coercive measures by the law and the cessation of all mass events such as fairs and rallies, to significantly reduce pollution from public events, industrial production, building construction, catering businesses and transport during the Level I response period, through the cooperation of the public and the government. The number of new confirmed cases nationwide has dropped sharply through the public and the government's tireless efforts. During the Level III response period, with the regular pandemic prevention, control measures and government support, industrial enterprises, catering restaurants and construction sites in Jilin Province have resumed work and production in varying degrees except for schools and other establishments.

In this study, we quantified the changes in the air quality of Changchun City before lockdownlockdown-after lockdown and discussed the possible impact of human activities on air quality. The study compared $\mathrm{PM}_{2.5}, \mathrm{PM}_{10}, \mathrm{NO}_{2}, \mathrm{SO}_{2}, \mathrm{CO}$ and $\mathrm{O}_{3}$ concentrations over four periods and compared them with those observed over the same period in 2017-2019, and also used the Potential Source Contribution Function (PSCF) method to identify and compare potential source areas of $\mathrm{PM}_{2.5}$, and also used backward trajectory models to explore the regional transport of pollutants during the lockdown period, in addition, to make the PSCF results more precise and more useful, some improvements have been made to the PSCF. This study aimed to assess changes in air quality in Changchun during the COVID-19 lockdown.

\section{METHODS}

\subsection{Research Area and Data Sources}

Changchun City is located at latitude $43^{\circ} 05^{\prime}-45^{\circ} 15^{\prime}$ North, longitude $124^{\circ} 18^{\prime}-127^{\circ} 05^{\prime}$ East, in the northern temperate zone of mid-latitude in the northern hemisphere, in the middle of the northeast region of the People's Republic of China, is the political, economic and cultural center of Jilin Province. Changchun borders Songyuan to the northwest, Siping to the southwest, Jilin to the southeast, and Heilongjiang Province to the northeast. According to the second national land survey results, the city has 20,604 square kilometers, with an urban area of 6,991 square kilometers and a planning area of 7,293 square kilometers. At the end of 2018, the built-up area of the city center was 3,676 square kilometers.

There are ten automatic air monitoring stations in Changchun, as shown in Fig. 1: Daishan Park (DP), High-Tech Zone Management Committee (HZMC), Economic Development Zone Environment Sanitary Administration (EESA), Jingyue Park (JYP), Bus Factory Hospital (BFH), Labour Park (LP), Garden Management Office (GMO), Institute of Posts and Telecommunications (IPT), Food Products Factory (FPF), and one clean control station named Shuaiwanzi (SWZ), which is located in the Shuangyang district of Changchun. 


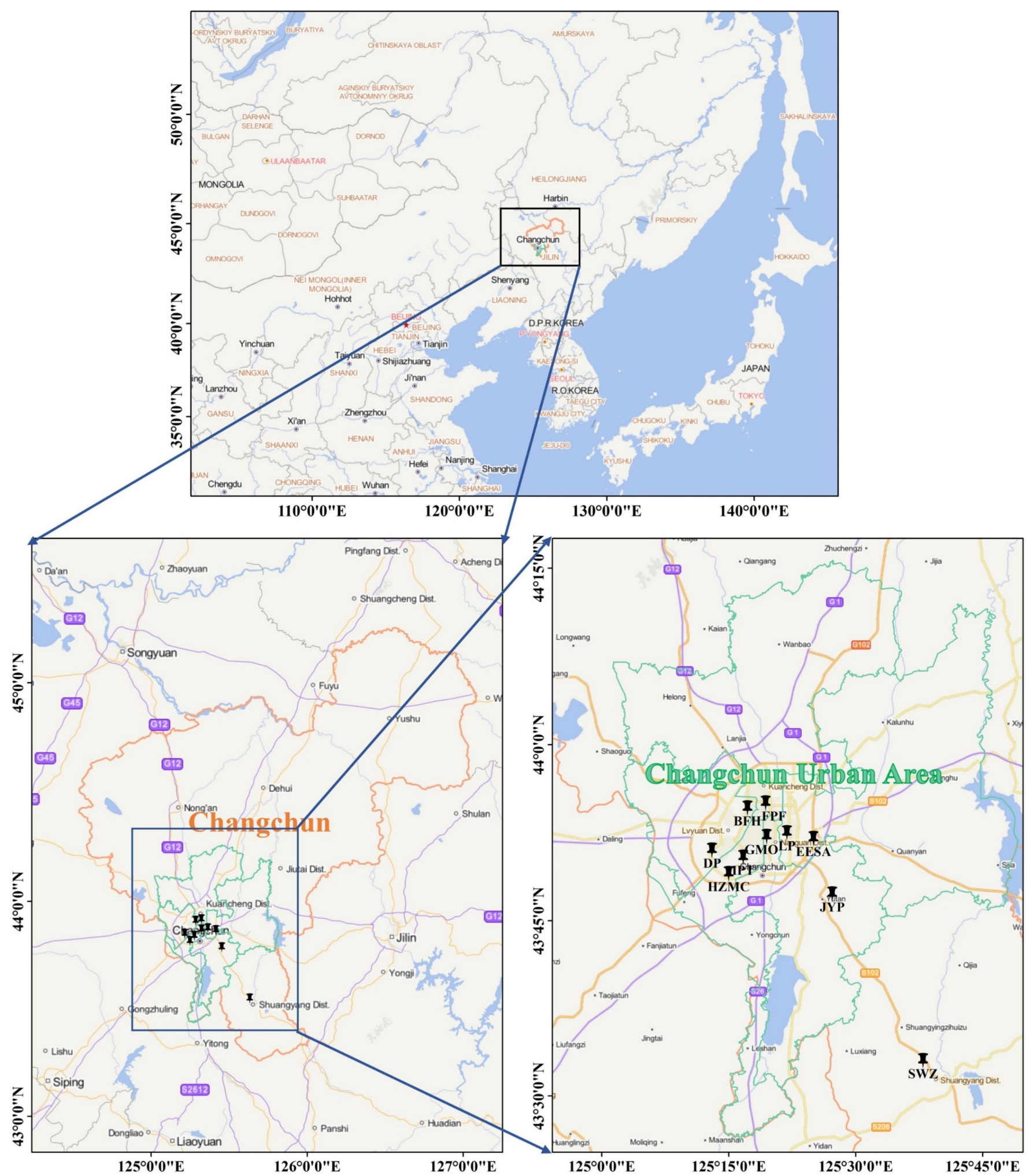

Fig. 1. The geographical location of the study area and location of atmospheric monitoring stations.

The concentration data of 6 pollutants used in this study from 1 January to 20 April in 20172020 were obtained from the daily hourly averages published by the Changchun Environmental Monitoring Station (https://www.aqistudy.cn/historydata/), and the meteorological data were obtained from data reported by the Changchun Meteorological Monitoring Station available on the China Meteorological Data Network (http://data.cma.cn/). 


\subsection{Potential Source Contribution Function (PSCF) Analysis and Backward Trajectory Analysis}

\subsubsection{Cluster analysis of backward trajectories}

In order to investigate the differences in regional transport of pollutants in Changchun over the four periods of the pandemic, the HYSPLIT (Hybrid Single Particle Lagrangian Integrated Trajectory) model developed by the National Oceanic and Atmospheric Administration (NOAA) and the Australian Bureau of Meteorology (BOM) was used to simulate the downtown area of Changchun. A $72 \mathrm{~h}$ backward trajectory at an altitude of $100 \mathrm{~m}$ was used to calculate 24 trajectories per day arriving in Changchun between 00:00-23:00 (LT) to analyze the atmospheric pollutant transport and dispersion trajectories. Other authors have done similar studies using the model in different areas (Stein et al., 2015; Szkop and Pietruczuk, 2017; Yassin et al., 2018).

A stepwise cluster analysis (SCA) algorithm is used to cluster the backward trajectories with specific optimizations to facilitate the analysis of the pollutant transport paths (Fang et al., 2018). In this algorithm, the trajectories with the most similar spatial similarity are merged based on the direction of transmission and each airflow trajectory's velocity. After repeated calculations and merging, several typical clustered trajectories were finally obtained. A total of 2088 trajectories were clustered throughout the study period to identify pollutants' transport paths over time. In this study, setting up the clustering resulted in 6 trajectories. The formula for the cluster analysis is as follows:

$$
\begin{aligned}
& D=\sqrt{\sum_{j=0}^{t} d_{j}^{2}} \\
& \text { SPVAR }=\sum_{i=1}^{x} \sum_{j=0}^{t} D_{i j}^{2}
\end{aligned}
$$

$T S V=\sum S P V A R$

In the Eqs. (1)-(3), $i$ is the number of trajectories, $j$ is the number of passing points, $t$ is the movement time of the airflow, $d_{j}$ is the distance between the jth point of two trajectories, $x$ is the number of trajectories in a cluster, $D$ is the distance between trajectories. So $D_{i j}$ represents the distance from the jth passing point of the ith trajectory to a corresponding point on the average trajectory. SPVAR is the spatial variation of each group of trajectories. TSV is the total spatial variation. The stepwise cluster analysis method allows neighboring points to be grouped together in a large statistical sample, and then trajectories with a high degree of similarity are selected for classification. The more classifications are made, the closer the situation is to the real situation and the less error the results will have.

\subsubsection{Potential Source Contribution Function (PSCF) analysis}

In this study, the Potential Source Contribution Factor (PSCF) was used to analyze the use of backward trajectories to locate pollution sources (Ding et al., 2017; Liu et al., 2019). The weighting factor $W_{i j}$ used in this study reduces the uncertainty in the PSCF results, called Weight Potential Source Contribution Function (WPSCF) (Polissar et al., 1999), and analyzes the areas of potential source contribution to $\mathrm{PM}_{2.5}$ in Changchun at different times of COVID-19, which shows us the pollutant transport paths before and after the pandemic. Before calculating the PSCF, the area which the trajectories pass through should first be grid-enabled. Different from the previous studies that the grid resolution was set to $1^{\circ} \times 1^{\circ}$ or $0.5^{\circ} \times 0.5^{\circ}$ (Meng et al., 2020; Yu et al., 2020), we set $0.1^{\circ} \times 0.1^{\circ}$ resolution in order to show more details of the potential source area. The following equation expresses the PSCF:

$P S C F_{i j}=\frac{m_{i j}}{n_{i j}}$ 
In Eq. (4), $n_{i j}$ is the sum of all trajectories' elapsed times through the $i j$ grid and $m_{i j}$ is the sum of the elapsed times of the trajectories in the ij grid where the concentration exceeds the limit. The limit value for $\mathrm{PM}_{2.5}$ used in the study is $75 \mu \mathrm{g} \mathrm{m}^{-3}$, which is the limit value for the second level of the Ambient Air Quality Standard (GB3095-2012) set by the Chinese Ministry of Ecology and Environment. Different limit values are used to determine different scenarios, so that different results can be derived for different pollution situations. For example, Zhao et al. (2020) set the $\mathrm{PM}_{2.5}$ limit value to $150 \mu \mathrm{g} \mathrm{m}^{-3}$ in their study of pollution events in the Beijing-TianjinHebei (BTH) region to determine the heavy pollution weather, and derived the results for the potential source area of $\mathrm{PM}_{2.5}$ in the $\mathrm{BTH}$ region under heavy pollution weather. However, due to the nature of the PSCF as a conditional probability function, for some grids with a small number of trajectories, the calculated PSCF value has a high degree of uncertainty. Therefore, in order to reduce errors and make the results more accurate, a weighting factor $W_{i j}$ is introduced, whose value will depend on the relationship between the sum of the transmission times of all trajectories in a given grid and the average dwell time of each grid. In this study, $W_{i j}$ is expressed by Eq. (5), then the PSCF expressed by Eq. (6) as:

$W_{i j}= \begin{cases}1.0 & n_{i j}>130 \\ 0.8 & 100<n_{i j} \leq 130 \\ 0.5 & 60<n_{i j} \leq 100 \\ 0.3 & 30<n_{i j} \leq 60 \\ 0.1 & 0<n_{i j} \leq 30\end{cases}$

$W P S C F_{i j}=P S C F_{i j} \times W_{i j}$

However, in combination with the results of some studies, it can be seen that even with the introduction of the weight function $\mathrm{W}_{\mathrm{ij}}$, the PSCF results still show high extremes on some grids that are further away from the study area (Wei et al., 2020; Zhao et al., 2020). This is because the number of trajectories passing through these grids is too small, and therefore, the total dwell time is shorter. We have therefore slightly changed the calculation method and defined the formula for the PSCF as follows:

$P S C F_{i j}=\frac{m_{i j}}{n_{\text {total }}}$

In Eq. (7), the total number is the sum of all trajectories' dwell times. A total of 2088 trajectories were used in this study, each with a transmission time of $72 \mathrm{~h}$, so the total is 150336 . the new WPSCF values were recalculated, while $W_{i j}$ remained unchanged. However, the improved method yields a relatively low WPSCF value, due to an oversized $n_{\text {total }}$ value, which does not affect the actual study's observations. By comparing the WPSCF values, the primary and secondary potential source areas of $\mathrm{PM}_{2.5}$ can be more easily identified.

\section{RESULTS AND DISCUSSION}

\subsection{Pollutant Concentration Changes over Time versus the Same Period}

\subsubsection{Contemporaneous comparison of pollutant concentrations in different years}

Fig. 2 shows the concentrations of the six major pollutants in four periods compared to the same period in 2017-2019. As can be seen from the graph, each pollutant's concentrations increased to varying degrees before and after the lockdown in 2020 compared to the same period in previous years and decreased to varying degrees during the lockdown period. The average concentration of $\mathrm{PM}_{2.5}$ in the pre-lockdown period increased by $10.7 \%, 107.3 \%$ and $68.2 \%$ compared with the same period in 2017-2019, and a larger increase in the Level III period than in previous years, with 

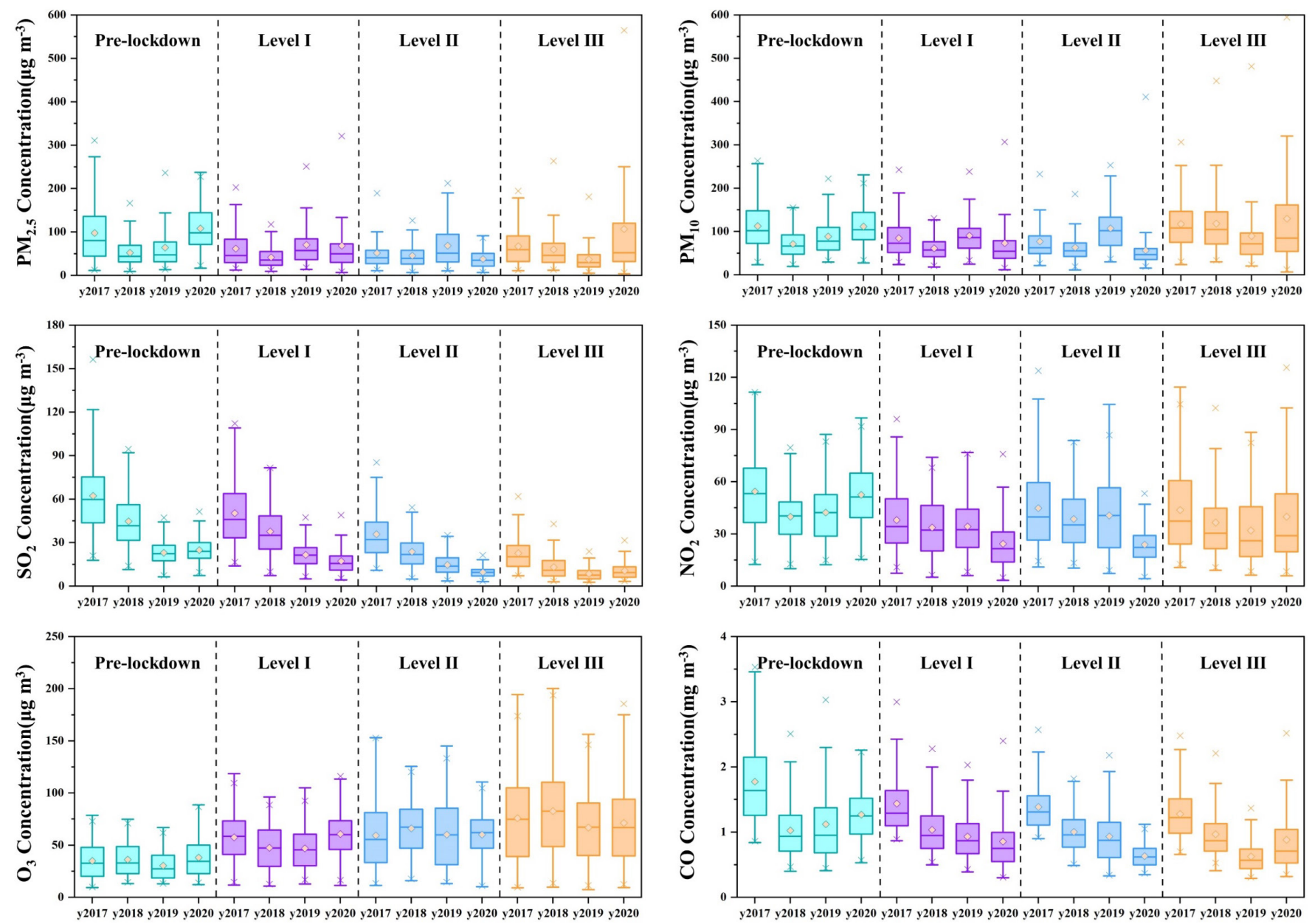

Fig. 2. Yearly changes of $\mathrm{PM}_{2.5}, \mathrm{PM}_{10}, \mathrm{SO}_{2}, \mathrm{NO}_{2}, \mathrm{O}_{3}$ and $\mathrm{CO}$ in Changchun during 1 January-20 April, 2020.

a maximum of $188.5 \%$. The concentrations of $\mathrm{PM}_{10}, \mathrm{NO}_{2}$ and $\mathrm{CO}$ in the pre-lockdown period and the Level III period also increased to varying degrees in the same period from 2017 to 2019, with an increase of $5.27 \%-56.1 \%$. During the level I period, $\mathrm{PM}_{2.5}$ increased by $10.7 \%$ and $63.8 \%$ respectively compared with the same period in 2017 and 2018, possibly because the lockdown began at the beginning of the Lunar New year in 2020, and the lockdown also made people stay at home and travel was greatly reduced. At this time, heating demand will increase, resulting in higher $\mathrm{PM}_{2.5}$ concentrations during the level I period than in previous years. In addition, strict measures and supervision against straw burning were implemented in 2018 , and the pollution of particulate matter was further controlled, making the concentration of $\mathrm{PM}_{2.5}$ in 2018 much lower than that in 2020 (Chen et al., 2019). During the lockdown period in 2020, all pollutant concentrations decreased to varying degrees compared to pre-lockdown period and the same period in the previous three years, except for $\mathrm{O}_{3}$, which increased compared to the same period in previous years. The concentrations of $\mathrm{PM}_{2.5}, \mathrm{PM}_{10}, \mathrm{SO}_{2}, \mathrm{NO}_{2}$, and $\mathrm{CO}$ were $36.9 \%, 34.6 \%, 30.5 \%, 53.8 \%$, and $32.5 \%$ lower in the Level I period and $65.0 \%, 49.4 \%, 61.2 \%, 54.7 \%$, and $50.1 \%$ lower in the Level II period, respectively, than in the pre-lockdown period. $\mathrm{PM}_{2.5}$ concentration decreasing by $26.7 \%, 17.0 \%$ and $44.5 \%$ during Level II compared to the same period in previous years, and $\mathrm{PM}_{10}$ decreasing during Level I compared to the same period in 2017 and 2019 by $13.9 \%$ and $19.2 \%$. $\mathrm{SO}_{2}$ decreased by $65.6 \%, 54.0 \%$ and $19.8 \%, \mathrm{NO}_{2}$ decreased by $36.2 \%, 27.8 \%$ and $29.1 \%$, CO decreased by $40.5 \%$, $17.3 \%$ and $8.2 \%$ respectively during Level I compared to the same period in the previous years. At the same time, we can also find that the concentrations of the other five pollutants, except $\mathrm{O}_{3}$, continued to decrease during Level II period continued to decrease, respectively by $44.6 \%, 22.6 \%$, $44.1 \%, 2.0 \%$ and $26.1 \%$ compared to Level I period, and decreased compared to all years in the same period (the decrease ranged from $10.5 \%$ to $72.9 \%$ ). As can be seen from the above results, 
the reduction in emissions caused by the lockdown is very significant, as the lockdown of factories and the reduction in traffic flow have led to a precipitous drop in pollutant emissions.

$\mathrm{O}_{3}$ concentration during Level I increased by $5.68 \%, 27.9 \%$ and $29.6 \%$ respectively compared with the same period in previous years, and the concentration increased from $38.1 \mu \mathrm{g} \mathrm{m}^{-3}$ of prelockdown to $60.8 \mu \mathrm{g} \mathrm{m}^{-3}$ of Level I, while the ozone concentration still increased slightly during Level II. This is because the traffic flow during Level I decreased significantly due to the lockdown compared with previous years. The concentration of $\mathrm{NO}_{2}$ decreased, and $\mathrm{NO}_{2}$ could not photolysis to generate more $\mathrm{NO}$ and atomic oxygen $\left(\mathrm{O}^{3} \mathrm{P}\right)$, which weakened the $\mathrm{O}_{3}$ titration reaction caused by $\mathrm{NO}$ and increased the $\mathrm{O}_{3}$ concentration. The mechanism of this process is reviewed and a targeted overview of $\mathrm{O}_{3}$ pollution in China is presented by Wang et al. (2017). The equation for the $\mathrm{O}_{3}$ titration reaction is as follows:

$\mathrm{NO}_{2}+h v \rightarrow \mathrm{NO}+\mathrm{O}\left({ }^{3} \mathrm{P}\right)$

$\mathrm{O}_{3}+\mathrm{NO} \rightarrow \mathrm{NO}_{2}+\mathrm{O}_{2}$

Ozone concentrations continued to increase after the resumption of work and production during Level III. This is due to the fact that $\mathrm{O}_{3}$ concentrations are higher in spring than in winter, even without the effect of lockdown, when temperatures are higher and solar radiation is stronger, and VOCs and $\mathrm{NO}_{\mathrm{x}}$ formed from vehicle exhaust catalyze ozone production with the combined effect of high temperatures as well as light radiation. A positive correlation between $\mathrm{O}_{3}$ concentration and temperature was also found in the results of other scholars' studies on cities in northeastern China and other countries, indicating that higher temperatures are conducive to the formation of $\mathrm{O}_{3}$ (Choi and Souri, 2015; Allu et al., 2020; Qin et al., 2021).

\subsubsection{Comparison of daily average pollutant values}

In order to observe the changes in pollutant concentrations over the time series and to quantify the impact of the lockdown on air pollutant levels, the percentage decrease in daily average values for each day of the year (DOY, day of the year) in 2020 compared to the three-year average for the same period of 2017-2019 was calculated. Fig. 3 shows the change in daily average values for the six pollutants for the same period in 2017-2019 and 2020, with the Level I and Level II periods being the lockdown periods, collectively referred to as "lockdown" in Fig. 3. Concentrations of all five pollutants except $\mathrm{O}_{3}$ decreased on most days during the lockdown, $\mathrm{PM}_{2.5}, \mathrm{PM}_{10}, \mathrm{SO}_{2}$, $\mathrm{NO}_{2}$, and $\mathrm{CO}$ decrease days accounted for $65.5 \%$ (36 days), 83.6\% (46 days), $100 \%$ ( 55 days), $94.6 \%$ (52 days), and $89.1 \%$ ( 49 days). The proportion of the reduction days exceed $50 \%$ accounted for $38.9 \%$ (14 days), 30.4\% (14 days), 70.9\% (39 days), 28.9\% (15 days) and 30.6\% (15 days) respectively. These results further confirmed that the lockdown has positively affected the reduction of pollutant concentrations in Changchun.

However, $\mathrm{O}_{3}$ concentrations rose on 35 of the 55 days during the lockdown, reaching $63.6 \%$, and there were no days with a drop more significant than $50 \%$ on the remaining days of decline, further confirming that ozone pollution intensified during the lockdown, and other studies have produced similar results (Sicard et al., 2020). One of the reasons for this is the reduction in NOx emissions from road traffic, which leads to lower $\mathrm{NO}$-induced $\mathrm{O}_{3}$ titration reactions and higher solar radiation due to lower particulate emissions caused by the lockdown, which also favors the formation of $\mathrm{O}_{3}$ (Ordonez et al., 2020). It is worth noting that when the pandemic was effectively controlled, the confirmed cases were cured and discharged one after another, the resumption of work and production in an orderly manner during the level III period, the resumption of operation of motor vehicles and non-road mobile machinery, and the acceleration of industrial enterprises to restore production capacity, we found that the concentration of all pollutants began to rebound to varying degrees from 1 April. Until 16 April, the concentration of each pollutant reached the maximum in the Level III period. The concentration of $\mathrm{PM}_{2.5}, \mathrm{PM}_{10}, \mathrm{SO}_{2}, \mathrm{NO}_{2}, \mathrm{CO}$ reached $402.6 \mu \mathrm{g} \mathrm{m}^{-3}, 392.1 \mu \mathrm{g} \mathrm{m}^{-3}, 24.7 \mu \mathrm{g} \mathrm{m}^{-3}, 91.8 \mu \mathrm{g} \mathrm{m}^{-3}$ and $2.03 \mathrm{mg} \mathrm{m}^{-3}$ respectively on 16 April, which was 8.7, 2.5, 2.1, 2.7, 2.3 times of the three-year average concentration on the same day from 2017 to 2019, respectively. At the same time, it can be seen from Fig. 2 that the average concentration of $\mathrm{PM}_{2.5}, \mathrm{PM}_{10}, \mathrm{SO}_{2}, \mathrm{NO}_{2}, \mathrm{CO}$ in Level III period is $106.8 \mu \mathrm{g} \mathrm{m}^{-3}, 129.8 \mu \mathrm{g} \mathrm{m}^{-3}$, 

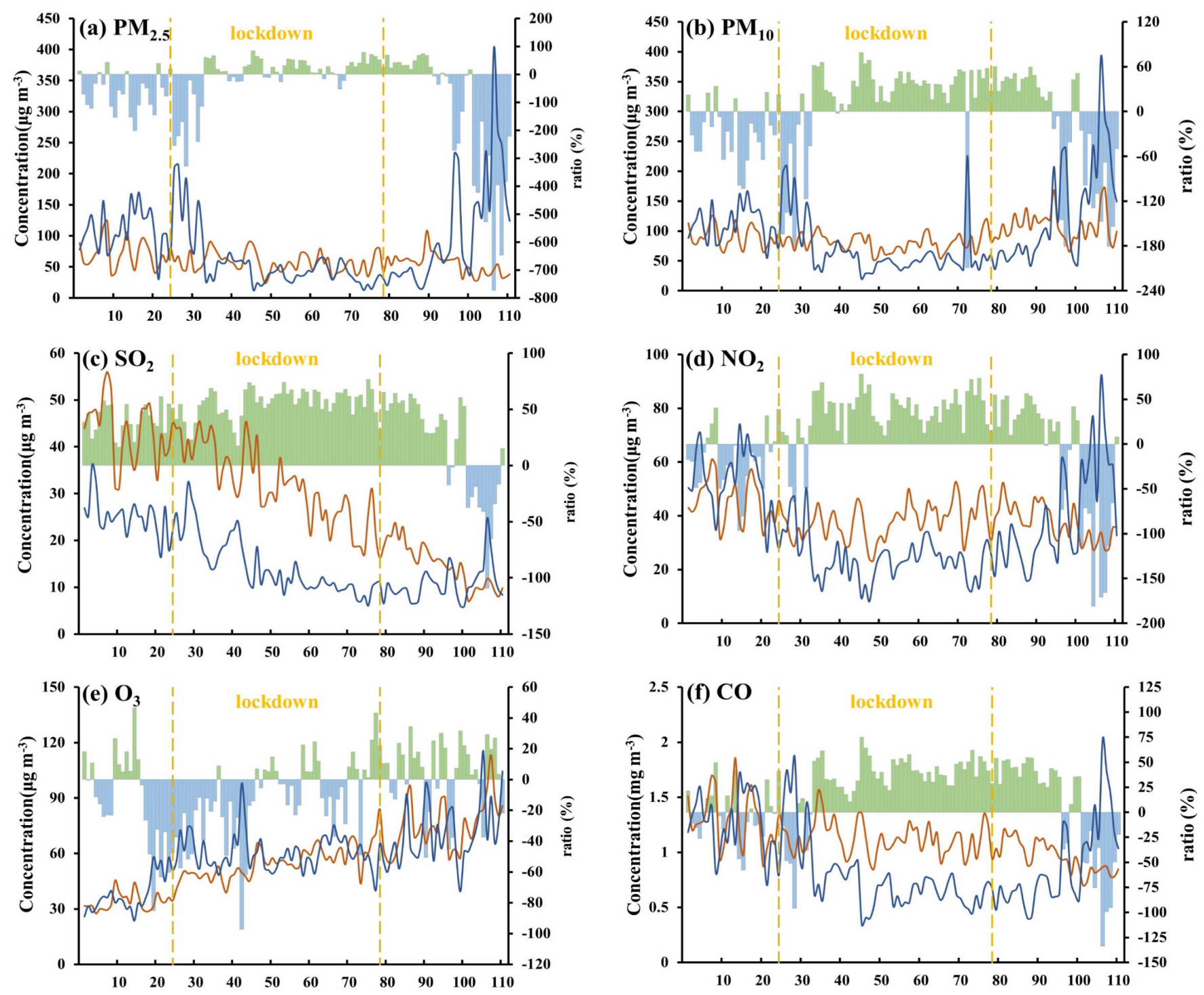

\section{DOY}

Decrease ratio(\%) - y2017-y2019-y2020

Fig. 3. The daily mean concentrations of $\mathrm{PM}_{2.5}, \mathrm{PM}_{10}, \mathrm{SO}_{2}, \mathrm{NO}_{2}, \mathrm{O}_{3}$, and CO from 1 January 2020 (Day of the year, $\mathrm{DOY}=1$ ) to $\mathrm{DOY}$ $=110$ (blue line) and in the same period over the three previous years (red line), and the percentage of decline in 2020 compared with the average of the previous three years (green represents the positive value, blue represents the negative value) in Changchun.

$10.6 \mu \mathrm{g} \mathrm{m}^{-3}, 39.9 \mu \mathrm{g} \mathrm{m}^{-3}$ and $0.88 \mathrm{mg} \mathrm{m}^{-3}$, respectively, which is $2.8,2.3,1.1,1.7,1.4$ times of the average value in Level II period, respectively. The above results show that the lockdown only temporarily reduced the concentration of pollutants, when production and life returned to normal, not only did not keep the air clean, but caused more serious pollution.

\subsubsection{Comparison of hourly mean pollutant concentrations}

To analyze the impact of changes in human activities brought by the lockdown on the trends in pollutant concentrations, Fig. 4 shows the rate of hourly and daily variations of six pollutants from 25 January to 19 March from 2017 to 2020. As shown in Figs. 4(a)-4(f), the hourly mean concentrations of all pollutants during the lockdown in 2020 have decreased significantly compared to the previous three years except for $\mathrm{O}_{3}$. However, $\mathrm{PM}_{2.5}$ and $\mathrm{PM}_{10}$ have increased partially compared to 2018 , which is consistent with the results in Section 3.1.1. Overall, all pollutants' daily trends 

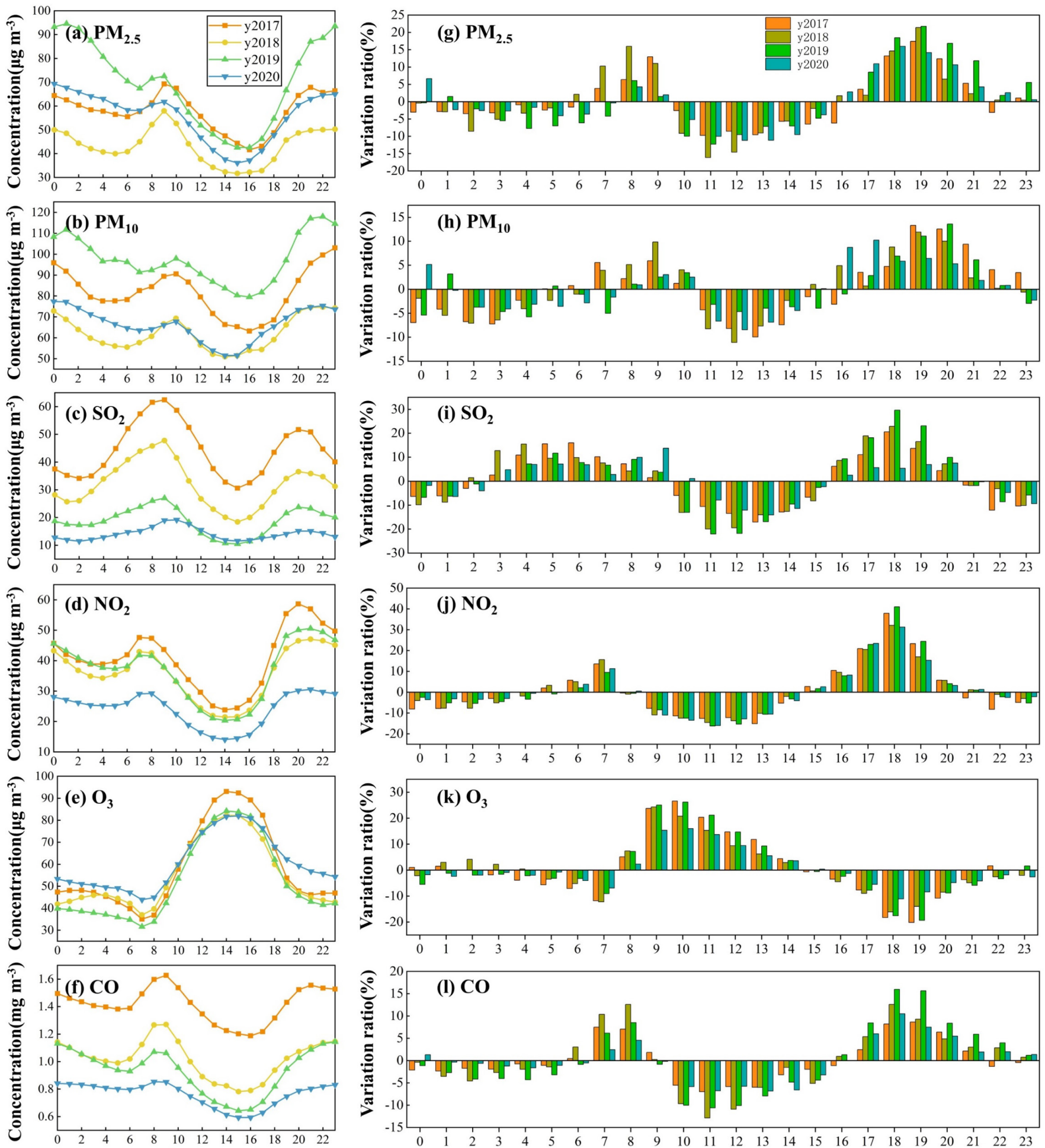

Fig. 4. The daily concentration changes and hourly variation ratio of $\mathrm{PM}_{2.5}, \mathrm{PM}_{10}, \mathrm{SO}_{2}, \mathrm{NO}_{2}, \mathrm{O}_{3}$, and $\mathrm{CO}$ from 25 January to 19 March, 2017-2020.

during the lockdown period were "double-peaked and double-valleyed" type during the lockdown period of 2017-2020, except for ozone, which was "single-peaked", and similar results were obtained in other studies (Chen et al., 2016). From Fig. 4(e), it can be seen that in the daily variation of $\mathrm{O}_{3}$ from 2017 to 2020, $\mathrm{O}_{3}$ reaches its daily minimum at 7:00 LT in each year with $35.1 \mu \mathrm{g} \mathrm{m}^{-3}$, $37.0 \mu \mathrm{g} \mathrm{m}^{-3}, 31.6 \mu \mathrm{g} \mathrm{m}^{-3}$, and $43.9 \mu \mathrm{g} \mathrm{m}^{-3}$, respectively, and then starts to increase. the daily peak of $\mathrm{O}_{3}$ occurs at 14:00 LT in 2017-2019 with $93.1 \mu \mathrm{g} \mathrm{m}^{-3}, 82.2 \mu \mathrm{g} \mathrm{m}^{-3}$, and $84.2 \mu \mathrm{g} \mathrm{m}^{-3}$, and in 2020 
it occurs at 15:00 LT with $81.7 \mu \mathrm{g} \mathrm{m}^{-3}$. For the results, the changes in human activity brought about by the lockdown did not have a disproportionate impact on the overall trend in daily concentration changes of pollutants. The second daily peak of $\mathrm{PM}_{2.5}, \mathrm{PM}_{10}$ and $\mathrm{CO}$ during the lockdown in 2020 occurs later (0:00 LT) than in the same period in previous years (20:00 and 23:00 LT), the first peak of $\mathrm{SO}_{2}$ and $\mathrm{NO}_{2}$ occurs later (10:00 LT) than in the same period in previous years (9:00 LT). The peak of $\mathrm{O}_{3}(15: 00 \mathrm{LT})$ was also delayed than in the same period in previous years (14:00 LT).

As can be seen from Figs. $4(\mathrm{~g})-4(\mathrm{I})$, the hourly rate of change of each pollutant during the 2020 lockdown is significantly lower than in previous years, and as can also be seen from Figs. 4(a)4(f), the trend of each pollutant becomes more moderate during the 2020 lockdown. For example, the maximum daily growth rate of $\mathrm{PM}_{2.5}$ during the lockdown in 2020 is $16.0 \%$, and the maximum daily growth rates for the same period in previous years are all higher than in 2020 (21.8\%, 21.4\%, $17.4 \%)$, the maximum daily growth rate of $\mathrm{PM}_{10}$ during the lockdown in 2020 is $10.3 \%$, compared to $13.3 \%, 11.9 \%$, respectively, for the same period in previous years. $13.6 \%$ and $\mathrm{SO}_{2}$ had a maximum daily growth rate of $13.8 \%$ during the 2020 lockdown, compared to $20.6 \%, 22.9 \%$ and $29.6 \%$, respectively for the same period in previous years. Similar patterns were observed to varying degrees for other pollutants, suggesting that the reduced intensity of human activity brought about by the lockdown reduced not only pollutant concentrations but also slowed the hourly rate of change in daily pollutant concentrations.

\subsection{Spatial Distribution of Pollutant Concentrations over Four Periods}

The average concentrations of six pollutants over four periods during the pandemic in Changchun were processed using the Kriging interpolation method in the Surfer software and the contour plots shown in Fig. 5 were plotted. It is clear from Fig. 5 that, except for $\mathrm{O}_{3}$, the other five pollutants showed a "high-low-low-high" trend over the four periods. The low concentrations of $\mathrm{SO}_{2}$ and $\mathrm{NO}_{2}$ at the edge of the city may be attributed to the high degree of vegetation cover (Shao et al., 2004; Wu et al., 2020), which is more evident in the Jingyuetan National Scenic Area is located to
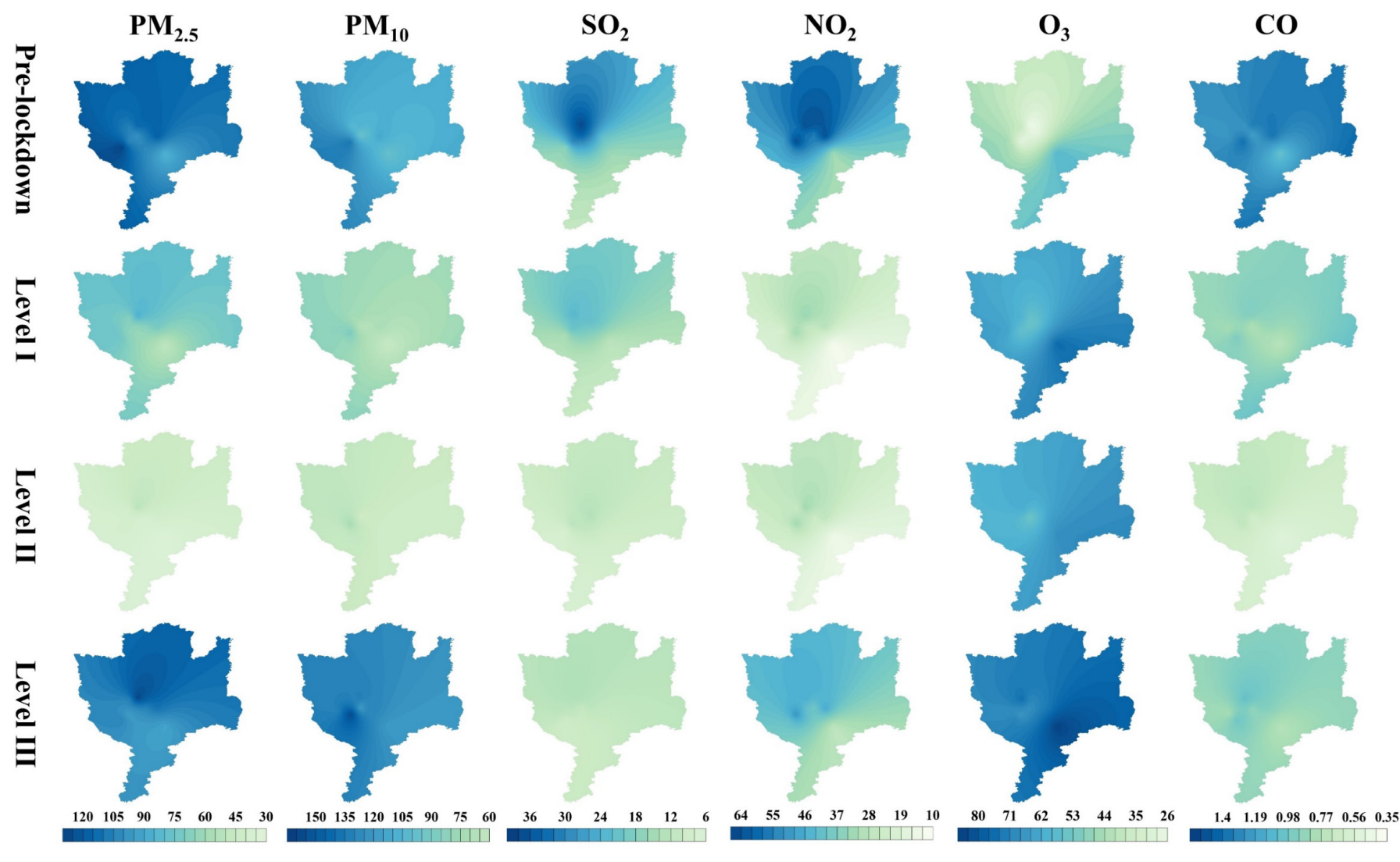

Fig. 5. Spatial distribution of the average mass concentration of 6 pollutants in four different study periods (CO is measured in $\mathrm{mg} \mathrm{m}^{-3}$, and other pollutants are measured in $\mu \mathrm{g} \mathrm{m}^{-3}$ ). 
the southeast. The concentrations of $\mathrm{NO}_{2}$ and $\mathrm{CO}$, which are the primary sources of traffic emissions, have fallen sharply citywide since the beginning of the lockdown, but a higher distribution trend in the central city can still be seen. During the lockdown, the decline in $\mathrm{SO}_{2}$ is not only the reduction in domestic and industrial emissions, but also due to the gradual weakening of heating in the spring (Ma et al., 2019).

For particulate matter, before the lockdown, particulate matter was always higher in the southwest of the city, which may be because there are more factories in the southwest of the city than in other areas emissions are higher. For $\mathrm{PM}_{2.5}$, the highest $\mathrm{PM}_{2.5}$ concentrations were found in the city center after the lockdown occurred. This is reflected in the highest $\mathrm{PM}_{2.5}$ concentrations at the FPF during Level I-Level III, whereas before the lockdown it was in the HZMC, probably due to the large number of emissions reduced by the work stoppage. Furthermore, even when work resumed at Level III, it was only partially resumed and there was still a long way to go before returning to pre-lockdown levels, resulting in higher $\mathrm{PM}_{2.5}$ concentrations in the north of the central city than in the south at Level III. For $\mathrm{PM}_{10}$, the southwest urban area is on the high side in all four periods, which is reflected in that the highest concentration before the lockdown is the HZMC, and the other three periods is the IPT, both of which are in the southwest of the urban area. The reason for this phenomenon is that $\mathrm{PM}_{10}$ is not only emitted by industrial enterprises but also affected by wind-blown dust, so even if the emission is controlled, it cannot control the natural factors.

For ozone, all four periods are reflected in overall high ozone concentrations in the southeast, which is reflected in the fact that the JYP has the highest average ozone concentration of all stations throughout the study period. The JYP has a high vegetation cover and low emissions, the vegetation releases large amounts of ozone precursors, such as VOCs (Mahilang et al., 2021), and the titration reaction is accelerated, resulting in elevated ozone concentrations in the urban area.

\subsection{Analysis of the Correlation between Meteorological Factors and Individual Pollutants}

The interaction between meteorological factors and pollutants plays an important role in the formation and dispersion of pollutants (Zhang et al., 2015). This study analyzed the correlations between six air pollutants and air temperature, air pressure and wind speed for four periods during the study period of 2020, as shown in Fig. 6. Pearson's correlation coefficient $r$ expresses the degree of correlation.

The results show that there is a positive correlation between $\mathrm{PM}_{2.5}, \mathrm{PM}_{10}, \mathrm{SO}_{2}, \mathrm{NO}_{2}, \mathrm{CO}$ before and after lockdown, which is because there are many industrial point sources in Changchun, the factory discharge is large, and the pollutants are affected by the same emission source. Before the lockdown, the correlation coefficients between $\mathrm{CO}$ and $\mathrm{PM}_{2.5}, \mathrm{PM}_{10}$ and $\mathrm{NO}_{2}$ were 0.974, 0.989 and 0.996 , respectively. The correlation coefficients between $\mathrm{NO}_{2}$ and $\mathrm{PM}_{2.5}, \mathrm{PM}_{10}$ were 0.991, and the correlation coefficients between $\mathrm{PM}_{2.5}$ and $\mathrm{PM}_{10}$ were 0.979 . After the end of the lockdown, there was a high positive correlation among the above five pollutants (correlation coefficient $\geq 0.719$ ). There was a negative correlation between $\mathrm{O}_{3}$ and other five pollutants in four periods. The negative correlation coefficients between $\mathrm{O}_{3}$ and $\mathrm{NO}_{2}$ were higher in the four periods $(-0.331,-0.427,-0.697,-0.35$, respectively), and there was also a negative correlation between $\mathrm{O}_{3}$ and $\mathrm{CO}\left(-0.31,-0.134,-0.447,-0.157\right.$, respectively). Before the lockdown, $\mathrm{O}_{3}$ negatively correlated with $\mathrm{PM}_{2.5}$ and $\mathrm{PM}_{10}$ (the correlation coefficient was -0.358 and -0.317 ).

Temperature and $\mathrm{O}_{3}$ are positively correlated before decapsulation and during Level $\mathrm{I}$, and the increase in $\mathrm{O}_{3}$ concentration with increasing temperature is consistent with most research findings (Raoufi et al., 2018; Ilić et al., 2020). However, a weak negative correlation was observed between Level II and Level III, possibly due to the rebound in concentrations of all other pollutants after decapsulation and a change in the proportion of ozone precursors, resulting in a decrease in the rate of ozone production after decapsulation, and the correlation showed negative results. The temperature was negatively correlated with the other five pollutants both before the lockdown and during Level I, probably because low temperatures increase the activity of emission sources such as coal-fired power plant heating. There is a negative correlation between temperature and other five pollutants before the lockdown and during the Level I period, which may be because low temperatures increase the activity of emission sources (such as heating in coal-fired power 


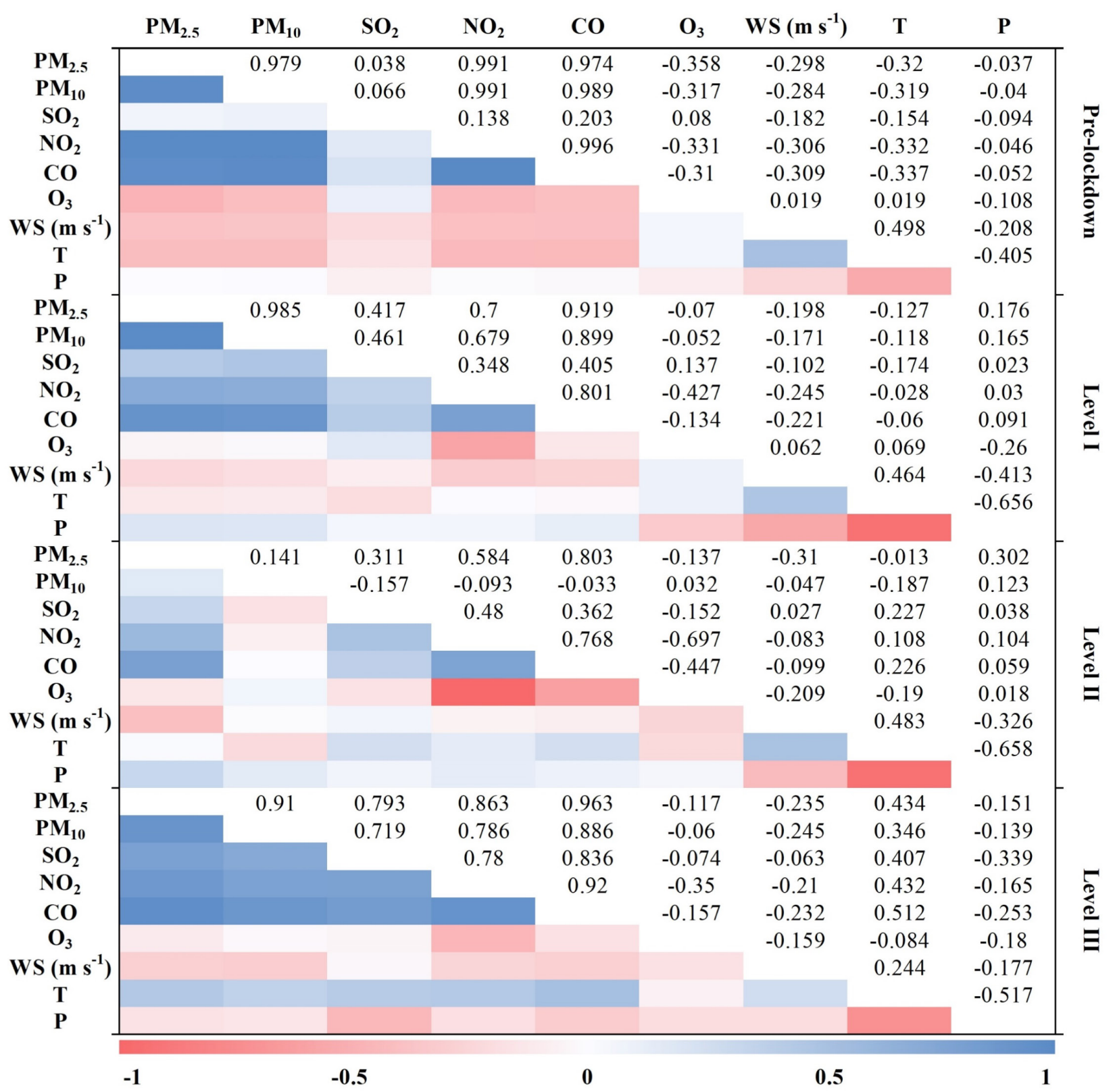

Fig. 6. Relationship between six pollutants and three meteorological elements (wind speed, temperature, atmospheric pressure).

plants). During the heating period, the concentration of pollutants will also become higher in Changchun because human-made sources' emission intensity has increased (He, 2017). However, the five pollutants' temperature dependence showed positive values during Level II $\left(\mathrm{SO}_{2}, \mathrm{NO}_{2}\right.$ $\mathrm{CO})$ and positive values during Level III $(0.346 \leq r \leq 0.512)$. Except for the positive $r$ value of $\mathrm{SO}_{2}$ and wind speed in Level II period (0.027, minimal), all pollutants are negative in other periods, and the other five pollutants are negative in all periods. The increase of wind speed is sometimes beneficial to the external transport of pollutants and can reduce the concentration of local pollutants to a certain extent (Chen et al., 2017; Fang et al., 2017), but it can also be seen that the absolute value of the correlation coefficient during the lockdown period is less than that before and after the lockdown. This is due to reduced local emissions during the lockdown, and the wind speed mainly affects local emissions. As far as atmospheric pressure is concerned, it is negatively correlated with pollutants before lockdown and during Level III. However, there is a positive correlation with the pollutants during the lockdown period, which can be attributed to the fact that the weakening of the pressure field is not conducive to disseminating pollutants (Chang et al., 2019; Li et al., 2019). 


\subsection{Clustering Analysis}

\subsubsection{Backward trajectory clustering results}

As shown in Fig. 7, a total of 2088 meteorological trajectories at the height of $100 \mathrm{~m}$ in Changchun's center over four periods were divided into six average trajectories using a stepwise clustering analysis procedure, based on the source and direction of the airflow. We have numbered the clustering results as trajectories 1-6. period-specific information for each cluster is shown in Table 1. Air currents with a higher percentage of total trajectories have a significant impact on air quality. As shown in the previous analysis, the lockdown plays a significant role in reducing pollutant levels in Changchun. Therefore, the mass concentrations of $\mathrm{PM}_{2.5}, \mathrm{CO}, \mathrm{NO}_{2}$ and $\mathrm{SO}_{2}$ corresponding to each trajectory were calculated.

Previous studies have shown that a higher percentage trajectory has a more significant impact on local air quality. From the results, the prevailing north-westerly winds before the lockdown resulted in the predominance of a north-westerly trajectory before the lockdown, with the highest percentage being trajectory $5(31.6 \%)$, which is shorter in length than the other trajectories and is influenced by the circulation of the land and sea winds from Inner Mongolia into Jilin province via northern Liaoning. The lowest percentage is for trajectory 2 (3.65\%), which is a long-distance transport, entering via Russia, Mongolia, Inner Mongolia and finally northwest of Jilin province. In the Level I period, after the lockdown began, the clustering changed significantly, with all trajectory starting points occurring in a westerly direction and little variation between trajectories $(2.34 \%-$ $12.2 \%)$, with the highest percentage being Trajectory 1 (23.3\%) from Heilongjiang across Inner Mongolia to Jilin Province and the lowest percentage being Trajectory 4 (11.1\%) from Russia after traveling through Mongolia and Inner Mongolia to Jilin Province. The clustering pattern continues to change during Level II, with the north-westerly trajectory no longer dominating than the
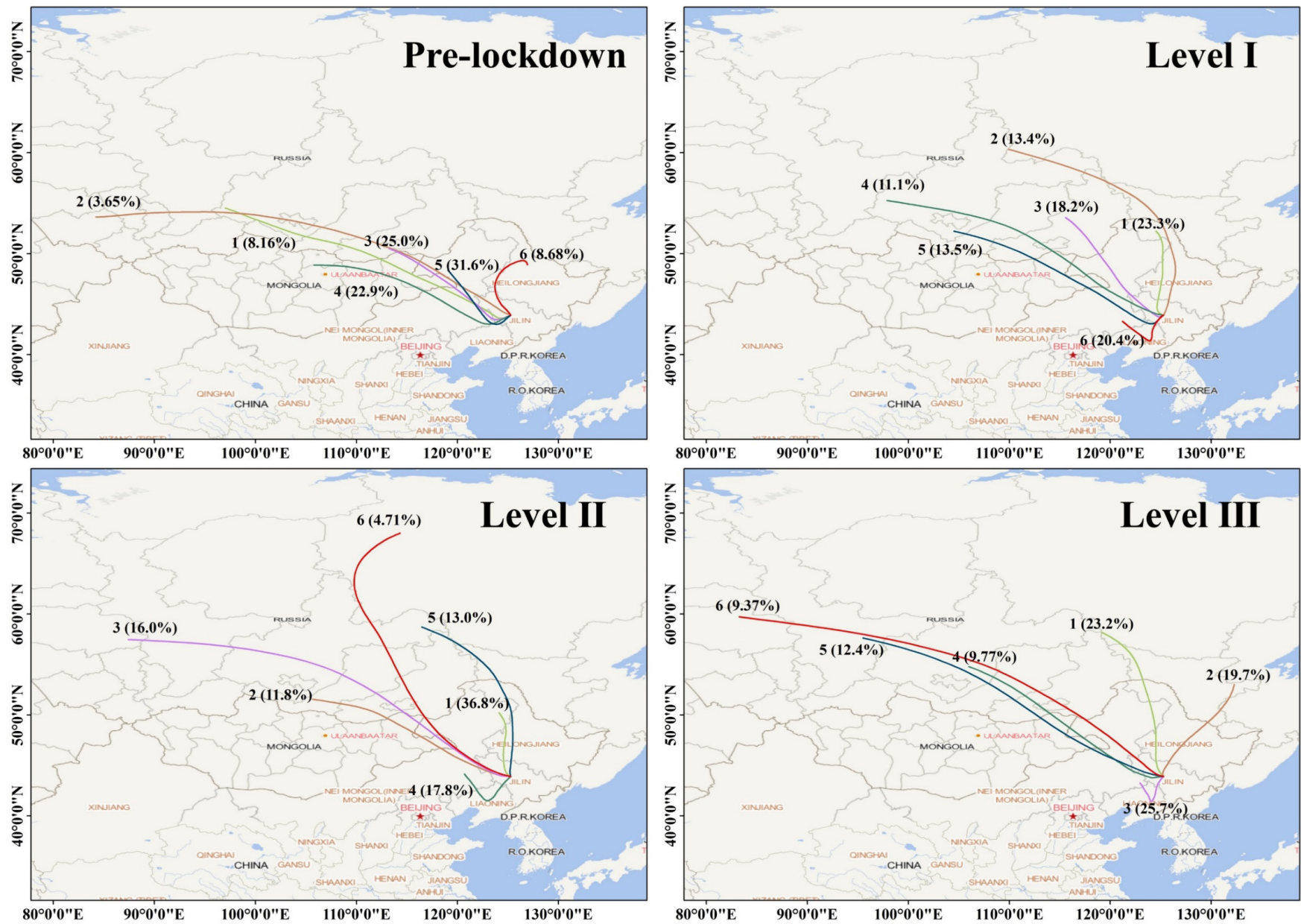

Fig. 7. Cluster distribution of backward trajectories for four study periods in Changchun during the 2020 pandemic. 


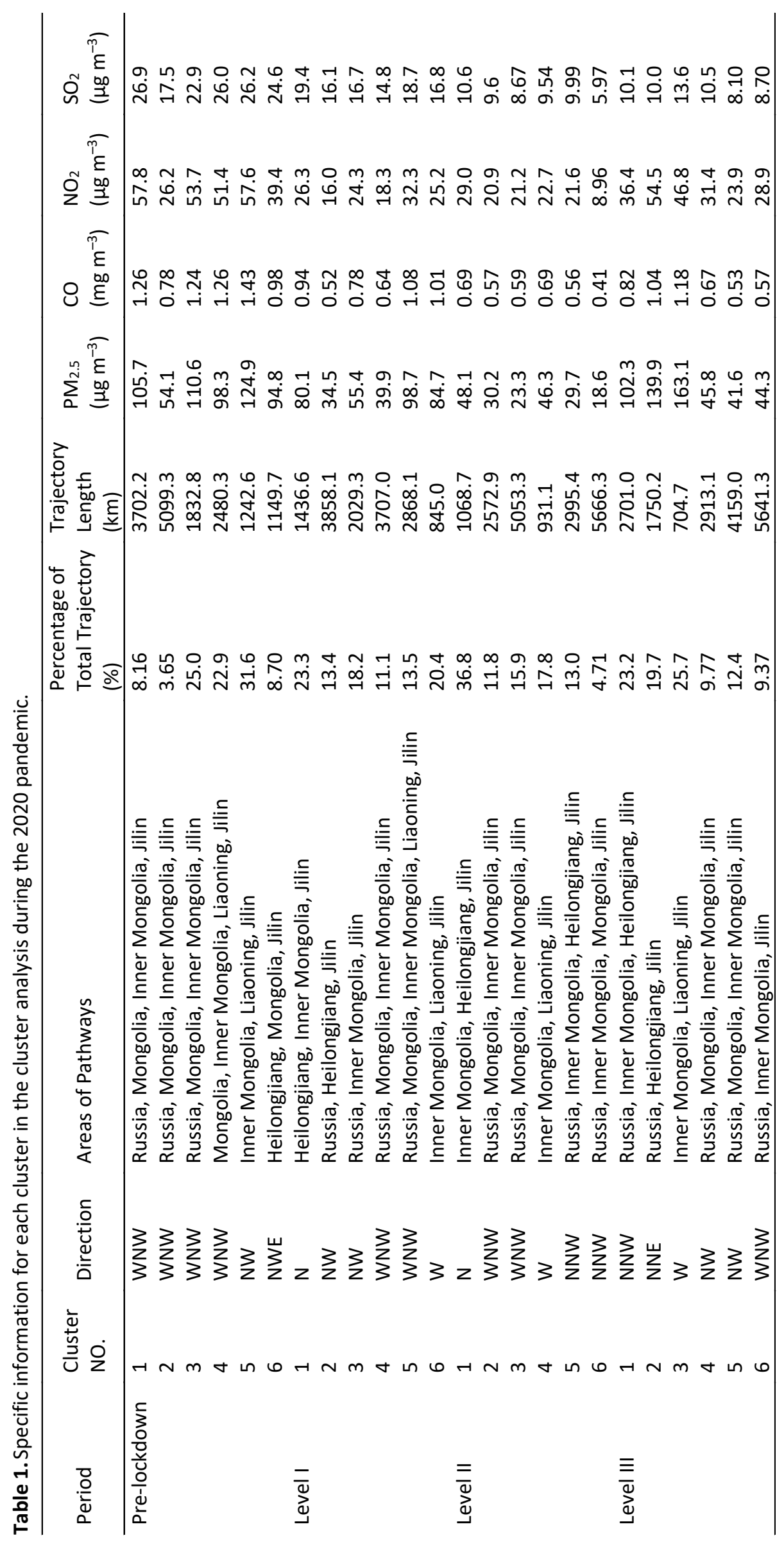


pre-lockdown and Level I trajectories. The share of the due north Trajectory 1 runs from Inner Mongolia through Heilongjiang and finally to Jilin province, rising to $36.8 \%$. During Level III, the north-westerly trajectory is still not dominant, but two high percentage trajectories, Trajectory 1 and Trajectory 2, occur, which are north-north-westerly and north-northeasterly respectively, and their combined percentage reaches $42.8 \%$. It can also be noted that the average concentrations of the four pollutant trajectories before lockdown were the highest of the four periods, decreasing during levels 1 and 2 and reaching their lowest values during Level II, before rebounding after the lockdown was lifted during Level III, which is consistent with the previous pollutant analysis.

The highest average mass concentrations of $\mathrm{PM}_{2.5}$ and $\mathrm{CO}$ before the lockdown were in Trajectory $5\left(124.9 \mu \mathrm{g} \mathrm{m}^{-3}, 1.43 \mathrm{mg} \mathrm{m}^{-3}\right)$ and the highest concentrations of $\mathrm{NO}_{2}$ and $\mathrm{SO}_{2}$ were in Trajectory $1\left(57.8 \mu \mathrm{g} \mathrm{m}^{-3}, 26.9 \mu \mathrm{g} \mathrm{m}^{-3}\right)$. The highest concentrations of $\mathrm{PM}_{2.5}, \mathrm{CO}, \mathrm{NO}_{2}$ in the Level I period were in Trajectory $5\left(98.7 \mu \mathrm{g} \mathrm{m}^{-3}, 1.08 \mathrm{mg} \mathrm{m}^{-3}, 32.3 \mu \mathrm{g} \mathrm{m}^{-3}\right)$ and $\mathrm{SO}_{2}$ in Trajectory 1 $\left(19.4 \mu \mathrm{g} \mathrm{m}^{-3}\right)$. During the Level II period, the highest pollutant concentration was in trajectory 1 $\left(48.1 \mu \mathrm{g} \mathrm{m}^{-3}, 0.69 \mathrm{mg} \mathrm{m}^{-3}, 29.0 \mu \mathrm{g} \mathrm{m}^{-3}, 10.6 \mu \mathrm{g} \mathrm{m}^{-3}\right)$. During Level III, the highest concentration of $\mathrm{PM}_{2.5}, \mathrm{CO}, \mathrm{SO}_{2}$ was in Trajectory $3\left(163.1 \mu \mathrm{g} \mathrm{m}^{-3}\right)\left(1.18 \mathrm{mg} \mathrm{m}^{-3}, 13.6 \mu \mathrm{g} \mathrm{m}^{-3}\right)$, and the highest concentration of $\mathrm{NO}_{2}$ was in Trajectory $2\left(54.5 \mu \mathrm{g} \mathrm{m}^{-3}\right)$. The above results show that the pollution situation in Changchun during the pandemic remains complex. Even though the lockdown has reduced local industrial and transport emissions, local particulate matter and CO emissions remain high due to the heating period during the pandemic. Dust aerosols from Inner Mongolia, together with anthropogenic air pollutants from passing areas, accompanied by north-westerly winds through Liaoning Province to reach Changchun, can affect particulate matter concentration in Changchun. Simultaneously, other countries transported from Russia and Mongolia to Changchun via Heilongjiang and Inner Mongolia also have high concentrations of industrial pollutants $\left(\mathrm{SO}_{2}\right.$, $\mathrm{NO}_{2}$ ), indicating that the long-distance transport of pollutants is also worthy of attention.

\subsubsection{Results of the Potential Source Contribution Function (PSCF)}

In order to further investigate the air quality trajectory and source characteristics of $\mathrm{PM}_{2.5}$ in four stages in Changchun, the source areas of $\mathrm{PM}_{2.5}$ pollution were qualitatively analyzed using the PSCF. The PSCF threshold for $\mathrm{PM}_{2.5}$ was set at $75 \mu \mathrm{g} \mathrm{m}^{-3}$, which is consistent with the average daily standard. Fig. 8 shows the results for the potential source contributors. Overall, the regional distribution of potential contributions to $\mathrm{PM}_{2.5}$ in Changchun is mainly concentrated in the Jilin, Inner Mongolia, Liaoning and Heilongjiang regions. There is also a small contribution from outside the northeast region. Changchun is influenced not only by the northeast region and nearby cities but also by long-distance transmission. Before the lockdown, the parts of potential source cities and regions in Changchun with high WPSCF values $(0.000047<$ WPSCF $<0.000275)$ are Siping, Tieling, eastern and southern parts of Baicheng, western and southern parts of Hinggan League, and Tongliao, and the parts with slightly higher WPSCF values $(0.000007<$ WPSCF $<0.000046)$ are Songyuan, Liaoyuan, southern parts of Meihekou, Shenyang, Fushun, Qiqihar, Daqing, a small part of southern Greater Khingan Range, and Chita Oblast in Russia, Sukhbaatar Province and eastern part of Eastern Province in Mongolia. After the start of the lockdown, the number of highvalue areas of potential sources in Changchun was significantly reduced, but there were some cities with still high WPSCF values, such as Siping and Baicheng $(0.000047<$ WPSCF $<0.000219)$, while new areas with slightly higher contribution values appeared in southern Liaoning $(0.000007$ $<$ WPSCF $<0.000046)$. For example, parts of Liaoyang and Anshan. High-value areas have largely disappeared during Level II, with only a few areas having slightly higher WPSCF values $(0.000007$ $<$ WPSCF < 0.000014), such as Songyuan, Siping, northern Qiqihar and southern Greater Khingan Range. After the lockdown was lifted, that is, during the Level III period, the resumption of work was carried out in an orderly manner, the pollution from human-made sources increased, and the high-value areas of WPSCF increased, and some cities became high-value areas again, such as Siping and Tieling $(0.000039<$ WPSCF $<0.000114)$. At the same time, Songyuan also became a new high-value area. In the areas with slightly higher WPSCF values $(0.000007<$ WPSCF $<$ 0.000038), Anshan, Dalian and the Bohai Sea in Liaoning, Qinhuangdao in Hebei, Chifeng in Inner Mongolia, and the north and west of Suihua in Heilongjiang have also been added.

In terms of potential source regions for $\mathrm{PM}_{2.5}$, the southwestern part of Jilin Province, the northwestern part of Liaoning Province and the southwestern part of Heilongjiang Province and the northwestern part of Inner Mongolia were the central potential source regions for $\mathrm{PM}_{2.5}$ in 

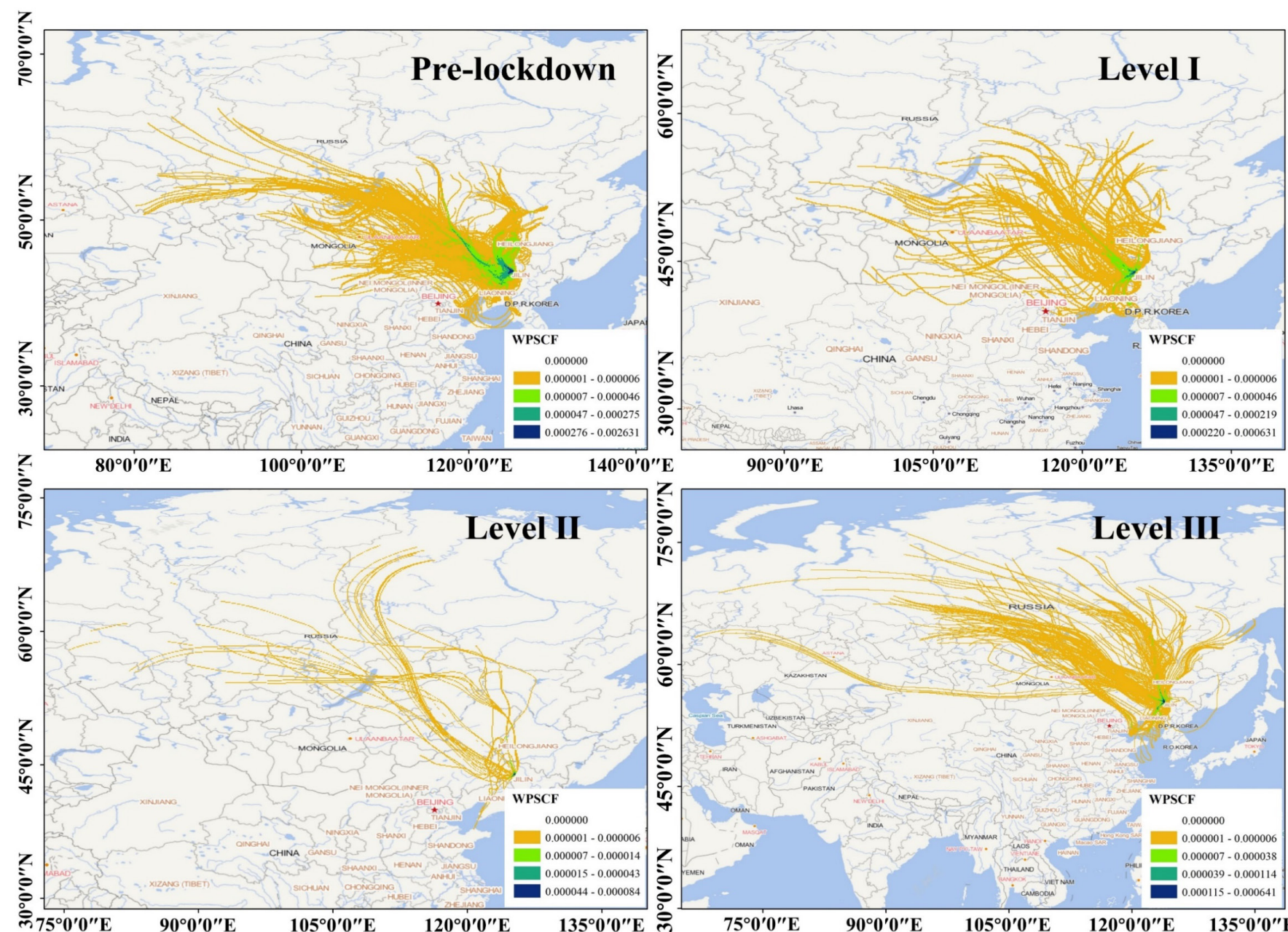

Fig. 8. Weighted potential source contribution function (WPSCF) values for $\mathrm{PM}_{2.5}$ in Changchun for the four study periods in 2020 pandemic.

Changchun during the pandemic. It is noteworthy that the largest proportion of the average trajectories were also mainly from these regions. Besides, air currents from the southwest are mainly short-haul and can therefore be a contribution from local sources. Northwestern Jilin Province, western Heilongjiang Province and southwestern Inner Mongolia are the main potential source areas for $\mathrm{PM}_{2.5}$ to Changchun's northwest. Most of the northwest airflow comes from southern Russia, Mongolia and is transported over relatively long distances due to the winter winds. Particulate matter may be physically lost during long-distance transport. The sandy areas in northwestern Inner Mongolia and the Gobi Desert region in central Mongolia can also be considered natural sources of $\mathrm{PM}_{2.5}$.

\section{CONCLUSIONS}

During the COVID-19 lockdown, human activity has been significantly reduced, leading to a significant reduction in industrial production, transport, construction and other activities, further reducing emissions. $\mathrm{PM}_{2.5}$ decreased by $26.7 \%, 17.0 \%$ and $44.5 \%$ during Level II compared to the same period of the previous three years, $\mathrm{PM}_{10}$ decreased by $13.9 \%$ and $19.2 \%$ during Level I compared to the same period of 2017 and 2019, respectively. $\mathrm{SO}_{2}$ decreased by $65.6 \%, 54.0 \%$, $19.8 \%, \mathrm{NO}_{2}$ decreased by $36.2 \%, 27.8 \%, 29.1 \%$, CO decreased by $40.5 \%, 17.3 \%, 8.20 \%$ during Level I compared to the same period of the previous three years, respectively. However, the concentration of particulate matter is still high during the Lunar New year, and the pollution before and after the lockdown is more serious than in the same period in previous years. During 
the pre-lockdown period, the concentrations of $\mathrm{PM}_{2.5}$ and $\mathrm{PM}_{10}$ increased compared with the same period of the previous three years, reaching the highest levels of $107.3 \%$ and $56.1 \%$, respectively, and the highest rising rates after the lockdown were $188.5 \%$ and $45.0 \%$, respectively. The concentration of $\mathrm{O}_{3}$ in the Level I period increased by $5.68 \%, 27.9 \%, 29.6 \%$, respectively, compared with the same period in 2017-2019, and the concentration increased from $38.1 \mu \mathrm{g} \mathrm{m}^{-3}$ in the prelockdown period to $60.8 \mu \mathrm{g} \mathrm{m}^{-3}$ in the Level I period. These results show that although the lockdown can reduce emissions, this environmental benefit is only temporary and can have other negative effects at the same time, indicating that the joint control of particulate matter and $\mathrm{O}_{3}$ is challenging.

During the lockdown in 2020, the "single-peak" trend of $\mathrm{O}_{3}$ and the "double-peak and doublevalley" trend of other pollutants still exist. The daily maximum growth rates of the six major pollutants during the lockdown period in 2020 were $16.0 \%, 10.3 \%, 13.8 \%, 31.2 \%, 16.0 \%, 10.5 \%$, respectively, which were lower than the daily maximum in the same period from 2017 to 2019. This shows that the lockdown not only leads to the decrease of pollutant concentration, but also reduces the diurnal variation rate of pollutant concentration, and the change trend is slower.

The correlation between each pollutant and meteorological elements shows that changes in the proportion of ozone precursors lead to a positive correlation between temperature and $\mathrm{O}_{3}$ during pre-lockdown and Level I, and a weak negative correlation during Level II and Level III. Emissions during the heating period resulted in a negative correlation between temperature and all five pollutants except $\mathrm{O}_{3}$, both before and during Level I, while the negative correlation between wind speed and these five pollutants diminished during the lockdown period attributed to a reduction in local emissions. There was a negative correlation between atmospheric pressure and pollutants before the lockdown and during Level III, but turn into a positive correlation during the lockdown.

The changes in human activities caused by the lockdown were not only reflected in the changes of pollutant concentrations, but also in the distribution on the spatial scale was partly changed, and the high concentration area of $\mathrm{PM}_{2.5}$ during Level III appeared in the northern part of the urban area which was different from other periods. Furthermore, the results of cluster analysis and PSCF analysis show that other northeastern cities (such as Siping, Shenyang, Qiqihar) have larger WPSCF values (WPSCF $\geq 0.000007$ ) for Changchun during the pandemic period, plus the high percentage trajectory transmitted from Heilongjiang and Liaoning around the Bohai Sea (up to $36.8 \%$ ), so the contribution from emissions caused by relatively close cities dominates. Meanwhile, the contribution of dust aerosols and industrial emissions to pollution in Changchun is also significant, which is due to the long-range transport from areas outside the northeast such as Mongolia and Russia through the winter northwest winds.

In conclusion, the lockdown has brought considerable environmental benefits, but this does not have a long-lasting effect. There is still a need to promote stricter measures continually such as energy structure and industrial restructuring in future pollution control efforts, implement stricter joint regional control of pollutants in Jilin Province even Northeast or North China in order to obtain better air quality.

\section{ACKNOWLEDGEMENTS}

The authors would like to thank the Ecological Environment Monitoring Center of Changchun, Jilin Province, for providing the data on pollutants. Additionally, the authors would like to thank the group members of Laboratory 537 and 142 of Jilin University.

\section{REFERENCES}

Allu, S.K., Srinivasan, S., Maddala, R.K., Reddy, A., Anupoju, G.R. (2020). Seasonal ground level ozone prediction using multiple linear regression (MLR) model. Model. Earth Syst. Environ. 6, 1981-1989. https://doi.org/10.1007/s40808-020-00810-0

Chang, S.C., Liao, C.H., Zeng, W.T., Yang, L.L., Yu, S.C., Chen, X., Zheng, J.P. (2019). Source apportionment of air pollutants for a typical pollution event in Zhaoqing. Environ. Sci. 40, 9. https://doi.org/10.13227/j.hjkx.201903237 (in Chinese) 
Chen, B., Lu, S.W., Zhao, Y.G., Li, S.N., Yang, X.B., Wang, B., Zhang, H.J. (2016). Pollution remediation by urban forests: $\mathrm{PM}_{2.5}$ reduction in Beijing, China. Pol. J. Environ. Stud. 25, 1873-1881. https://doi.org/10.15244/pjoes/63208

Chen, W., Tong, D.Q., Dan, M., Zhang, S., Zhang, X., Pan, Y. (2017). Typical atmospheric haze during crop harvest season in northeastern China: A case in the Changchun region. J. Environ. Sci. 54, 101-113. https://doi.org/10.1016/j.jes.2016.03.031

Chen, W.W., Li, J.W., Bao, Q.Y., Gao, Z.T., Cheng, T.H., Yu, Y. (2019). Evaluation of straw open burning prohibition effect on provincial air quality during October and November 2018 in Jilin Province. Atmosphere 10, 375. https://doi.org/10.3390/atmos10070375

Choi, Y., Souri, A.H. (2015). Seasonal behavior and long-term trends of tropospheric ozone, its precursors and chemical conditions over Iran: A view from space. Atmos. Environ. 106, 232240. https://doi.org/10.1016/j.atmosenv.2015.02.012

Ding, X.X., Kong, L.D., Du, C.T., Zhanzakova, A., Fu, H.B., Tang, X.F., Wang, L., Yang, X., Chen, J.M., Cheng, T.T. (2017). Characteristics of size-resolved atmospheric inorganic and carbonaceous aerosols in urban Shanghai. Atmos. Environ. 167, 625-641. https://doi.org/10.1016/j.atmosen v.2017.08.043

Fang, C.S., Zhang, Z.D., Jin, M.Y., Zou, P.C., Wang, J. (2017). Pollution characteristics of PM 2.5 aerosol during haze periods in Changchun, China. Aerosol Air Qual. Res. 17, 888-895. https://doi.org/10.4209/aaqr.2016.09.0407

Fang, C.S., Gao, J.L., Wang, D.L., Wang, D.S., Wang, J. (2018). Optimization of stepwise clustering algorithm in backward trajectory analysis. Neural Comput. Appl. 32, 109-115. https://doi.org/ 10.1007/s00521-018-3782-9

He, H.D. (2017). Multifractal analysis of interactive patterns between meteorological factors and pollutants in urban and rural areas. Atmos. Environ. 149, 47-54. https://doi.org/10.1016/j.atm osenv.2016.11.004

Ilić, P., Popović, Z., Nešković Markić, D. (2020). Assessment of Meteorological effects and ozone variation in urban area. Ecol. Chem. Eng. S 27, 373-385. https://doi.org/10.2478/eces-20200024

Li, L.Y., Yan, D.Y., Xu, S.H., Huang, M.L., Wang, X.X., Xie, S.D. (2017). Characteristics and source distribution of air pollution in winter in Qingdao, eastern China. Environ. Pollut. 224, 44-53. https://doi.org/10.1016/j.envpol.2016.12.037

Li, L., Li, Q., Huang, L., Wang, Q., Zhu, A., Xu, J., Liu, Ziyi, Li, H., Shi, L., Li, R., Azari, M., Wang, Y., Zhang, X., Liu, Zhiqiang, Zhu, Y., Zhang, K., Xue, S., Ooi, M.C.G., Zhang, D., Chan, A. (2020). Air quality changes during the COVID-19 lockdown over the Yangtze River Delta Region: An insight into the impact of human activity pattern changes on air pollution variation. Sci. Total Environ. 732, 139282. https://doi.org/10.1016/j.scitotenv.2020.139282

Li, X., Gao, Z.Q., Li, Y.B., Gao, C.Y., Ren, J.Z., Zhang, X.Y. (2019). Meteorological conditions for severe foggy haze episodes over north China in 2016-2017 winter. Atmos. Environ. 199, 284-298. https://doi.org/10.1016/j.atmosenv.2018.11.042

Liu, X.Y., Zhang, Y.L., Peng, Y.R., Xu, L.L., Zhu, C.M., Cao, F., Zhai, X.Y., Mozammel Haque, M., Yang, C., Chang, Y.H., Huang, T., Xu, Z.F., Bao, M.Y., Zhang, W.Q., Fan, M.Y., Lee, X.H. (2019). Chemical and optical properties of carbonaceous aerosols in Nanjing, eastern China: Regionally transported biomass burning contribution. Atmos. Chem. Phys. 19, 11213-11233. https://doi.org/10.5194/ acp-19-11213-2019

Ma, X.Y., Jia, H.L., Sha, T., An, J.L., Tian, R. (2019). Spatial and seasonal characteristics of particulate matter and gaseous pollution in China: Implications for control policy. Environ. Pollut. 248, 421428. https://doi.org/10.1016/j.envpol.2019.02.038

Mahilang, M., Deb, M.K., Pervez, S. (2021). Biogenic secondary organic aerosols: A review on formation mechanism, analytical challenges and environmental impacts. Chemosphere 262, 127771. https://doi.org/10.1016/j.chemosphere.2020.127771

Meng, F.H., Wang, J., Li, T.N., Fang, C.S. (2020). Pollution characteristics, transport pathways, and potential source regions of $\mathrm{PM}_{2.5}$ and $\mathrm{PM}_{10}$ in Changchun City in 2018. Int. J. Environ. Res. Public Health 17, 6585. https://doi.org/10.3390/ijerph17186585

Mofijur, M., Fattah, I.M.R., Alam, M.A., Islam, A.B.M.S., Ong, H.C., Rahman, S.M.A., Najafi, G. Ahmed, S.F., Uddin, M.A., Mahlia, T.M.I. (2021). Impact of COVID-19 on the social, economic, environmental and energy domains: Lessons learnt from a global pandemic. Sustain. Prod. 
Consum. 26, 343-359. https://doi.org/10.1016/j.spc.2020.10.016

National Aeronautics and Space Administration (NASA) (2020). The Earth Observatory. https://earthobservatory.nasa.gov/images/146362/airborne-nitrogen-dioxide-plummets-overchina (accessed 12 December 2020).

Ordonez, C., Garrido-Perez, J.M., Garcia-Herrera, R. (2020). Early spring near-surface ozone in Europe during the COVID-19 shutdown: Meteorological effects outweigh emission changes. Sci. Total Environ. 747, 141322. https://doi.org/10.1016/j.scitotenv.2020.141322

Otmani, A., Benchrif, A., Tahri, M., Bounakhla, M., Chakir, E.M., El Bouch, M., Krombi, M. (2020). Impact of COVID-19 lockdown on $\mathrm{PM}_{10}, \mathrm{SO}_{2}$ and $\mathrm{NO}_{2}$ concentrations in Sale City (Morocco). Sci. Total Environ. 735, 139541. https://doi.org/10.1016/j.scitotenv.2020.139541

Polissar, A.V., Hopke, P.K., Paatero, P., Kaufmann, Y.J., Hall, D.K., Bodhaine, B.A., Dutton, E.G. (1999). The aerosol at Barrow, Alaska: Long-term trends and source locations. Atmos. Environ. 33, 2441-2458. https://doi.org/10.1016/S1352-2310(98)00423-3

Qin, T., Wang, J., Li, R., Fang, C. (2021). Diurnal and inter-annual variability of surface ozone in Baicheng region, China. Tellus Ser. B 73, 1-10. https://doi.org/10.1080/16000889.2021.1894879

Raoufi, S.S., Goharnejad, H., Niri, M.Z. (2018). Air pollution effects on climate and air temperature of Tehran city using remote sensing data. Asian J. Water Environ. Pollut. 15, 79-87. https://doi.org/10.3233/ajw-180020

Shao, T.Y., Zhou, Z.X., Wang, P.C., Tang, W.P., Liu, X.Q., Hu, X.Y. (2004). Relationship between urban green-land landscape patterns and air pollution in the central district of Yichang city. Chin. J. Appl. Ecol. 15, 691-696. (in Chinese)

Shen, X.Y., Cai, C.K., Li, H. (2020). Socioeconomic restrictions slowdown COVID-19 far more effectively than favorable weather-evidence from the satellite. Sci. Total Environ. 748, 141401. https://doi.org/10.1016/j.scitotenv.2020.141401

Sicard, P., De Marco, A., Agathokleous, E., Feng, Z.Z., Xu, X.B., Paoletti, E., Rodriguez, J.J.D., Calatayud, V. (2020). Amplified ozone pollution in cities during the COVID-19 lockdown. Sci. Total Environ. 735, 139542. https://doi.org/10.1016/j.scitotenv.2020.139542

Stein, A.F., Draxler, R.R., Rolph, G.D., Stunder, B.J.B., Cohen, M.D., Ngan, F. (2015). NOAA'S HYSPLIT atmospheric transport and dispersion modeling system. Bull. Am. Meteorol. Soc. 96, 20592077. https://doi.org/10.1175/BAMS-D-14-00110.1

Szkop, A., Pietruczuk, A. (2017). Analysis of aerosol transport over southern Poland in August 2015 based on a synergy of remote sensing and backward trajectory techniques. J. Appl. Remote Sens. 11, 016039. https://doi.org/10.1117/1.JRS.11.016039

Tian, H., Liu, Y., Li, Y., Wu, C.-H., Chen, B., Kraemer, M.U.G., Li, B., Cai, J., Xu, B., Yang, Q., Wang, B., Yang, P., Cui, Y., Song, Y., Zheng, P., Wang, Q., Bjornstad, O.N., Yang, R., Grenfell, B.T., Pybus, O.G., et al. (2020). An investigation of transmission control measures during the first 50 days of the COVID-19 epidemic in China. Science 368, 638-642. https://doi.org/10.1126/science.abb6105

Wang, T., Xue, L., Brimblecombe, P., Lam, Y.F., Li, L., Zhang, L. (2017). Ozone pollution in China: A review of concentrations, meteorological influences, chemical precursors, and effects. Sci. Total Environ. 575, 1582-1596. https://doi.org/10.1016/j.scitotenv.2016.10.081

Wei, W., Zang, J.X., Wang, X.Q., Cheng, S.Y. (2020). Peroxyacetyl nitrate (PAN) in the border of Beijing, Tianjin and Hebei of China: Concentration, source apportionment and photochemical pollution assessment. Atmos. Res. 246, 105106. https://doi.org/10.1016/j.atmosres.2020.105 106

Wen, W., Ma, X., Tang, Y.X., Wei, P., Wang, J.K., Guo, C.W. (2020). The impacts of meteorology on source contributions of air pollution in winter in Beijing, 2015-2017 changes. Atmos. Pollut. Res. 11, 1953-1962. https://doi.org/10.1016/j.apr.2020.07.029

Wu, D., Gong, J.H., Liang, J.M., Sun, J., Zhang, G.Y. (2020). Analyzing the influence of urban street greening and street buildings on summertime air pollution based on street view image data. ISPRS Int. Geo-Inf. 9, 500. https://doi.org/10.3390/ijgi9090500

Xu, K.J., Cui, K.P., Young, L.H., Wang, Y.F., Hsieh, Y.K., Wan, S., Zhang, J.J. (2020). Air quality index, indicatory air pollutants and impact of COVID-19 event on the air quality near central China. Aerosol Air Qual. Res. 20, 1204-1221. https://doi.org/10.4209/aaqr.2020.04.0139

Yassin, M.F., Almutairi, S.K., Al-Hemoud, A. (2018). Dust storms backward Trajectories' and source identification over Kuwait. Atmos. Res. 212, 158-171. https://doi.org/10.1016/j.atmosres.201 8.05.020 
Yu, H., Feng, J.L., Su, X.F., Li, Y., Sun, J.H. (2020). A seriously air pollution area affected by anthropogenic in the central China: Temporal-spatial distribution and potential sources. Environ. Geochem. Health. 42, 3199-3211. https://doi.org/10.1007/s10653-020-00558-7

Zhang, H.L., Wang, Y.G., Hu, J.L., Ying, Q., Hu, X.M. (2015). Relationships between meteorological parameters and criteria air pollutants in three megacities in China. Environ. Res. 140, 242-254. https://doi.org/10.1016/j.envres.2015.04.004

Zhang, J.J., Cui, K.P., Wang, Y.F., Wu, J.L., Huang, W.S., Wan, S., Xu, K.J. (2020). Temporal variations in the air quality index and the impact of the COVID-19 event on air quality in western China. Aerosol Air Qual. Res. 20, 1552-1568. https://doi.org/10.4209/aaqr.2020.06.0297

Zhao, N., Wang, G., Li, G.H., Lang, J.L., Zhang, H.Y. (2020). Air pollution episodes during the COVID19 outbreak in the Beijing-Tianjin-Hebei region of China: An insight into the transport pathways and source distribution. Environ. Pollut. 267, 115617. https://doi.org/10.1016/j.envpol.2020.1 15617 